Talía. Revista de estudios teatrales

ISSN-e: 2659-806X

http://dx.doi.org/10.5209/TRET.63218

\title{
Calderón y la censura
}

\author{
Germán Vega García-Luengos*
}

Recibido: 26 de enero de 2019 / Aceptado: 7 de febrero de 2019

Resumen. El trabajo considera los diferentes aspectos que la censura plantea en la obra, y la vida, de Calderón: desde la que ejerció sobre sí mismo, y que debió de guiar algunos de sus frecuentes procesos de reescritura o incluso algunos repudios, hasta las "oficiales" que recibieron sus obras para ser representadas. Los motivos doctrinales y morales están detrás de la mayoría de las localizadas, pero también las hay impuestas por la política, e incluso por quejas de particulares. Asimismo, se ofrece una visión de las aprobaciones de los volúmenes calderonianos, donde la censura deja paso a una exaltación cada vez mayor del dramaturgo, hasta ser propuesto como arma contra los enemigos del teatro. El último apartado completa el panorama con la atención a su desempeño como censor.

Palabras clave: Censura, teatro, Calderón de la Barca, licencias, aprobaciones

\section{Calderón and the Censorship}

\begin{abstract}
The work considers the different aspects that censorship proposes in the dramatic work, and life, of Calderón: from the one that was exerted on himself, and that must have guided some of his frequent processes of rewriting or even some repudiations, to the official censorship that his works received in order to be represented. The doctrinal and moral reasons are behind most of the localized cases, but there are also those imposed by politics, and even by complaints from individuals. Likewise, a view of the approvals of the Calderonian volumes is offered, where the censorship gives way to an increasing exaltation of the playwright, until being proposed as a weapon against the enemies of the theater. Last section completes the panorama with attention to his performance as a censor.
\end{abstract}

Keywords: Censorship, Theater, Calderón de la Barca, Licenses, Approvals

Cómo citar: Vega García-Luengos, G. (2019). Calderón y la censura, en Talía. Revista de estudios teatrales, 1, 87-109

\section{Introducción}

Las relaciones de Calderón con la censura, como concepto o como ejercicio concreto, ofrecen múltiples caras, ilustrativas todas ellas no solo de los límites que la época ponía a la creatividad de los artistas sino también de las relaciones entre ellos. En él se da la mayoría de los supuestos del control que en ese tiempo y espacio que llamamos Siglo de Oro se desplegó para estrechar las posibilidades de expresión de quienes se encargaban de elaborar los textos dramáticos, una pieza fundamental

* Universidad de Valladolid. 
de la actividad ociosa que cautivaba a amplios sectores de la sociedad. La enorme capacidad del teatro de influir como ninguna otra arte o medio de comunicación en las mentes de los receptores incitó al poder a utilizarlo para sus fines de ostentación, publicidad y celebración; e hizo lo posible por tenerlo vigilado para que cumpliera esos objetivos y para que nada de lo que se dijera o se viera en los escenarios pudiera atentar contra la doctrina y la moral católicas. Por causas religiosas o políticas, las representaciones y ediciones estuvieron en el punto de mira de la acechante censura. Es una historia que necesita ser mejor conocida, pero que fue posible porque el género dramático, mal que bien, logró superar la "censura a la totalidad" que pretendió con denuedo el despliegue de voces y escritos que se conoce como la controversia por la licitud moral del teatro. Precisamente, la obra de Calderón dio pie a uno de sus capítulos más encendidos, a raíz de la "Aprobación" del Padre Manuel Guerra que encabezó la labor editorial de Vera Tassis en 1682.

Estas páginas pretenden una aproximación a los distintos aspectos que la censura plantea en la obra, y la vida, de Calderón. En el intento de ofrecer una síntesis lo más completa posible, me ha parecido conveniente dedicar las primeras consideraciones a la autocensura, a las que seguirán las relativas a las censuras de representaciones, para finalizar con las de los impresos. En su elaboración han sido de gran ayuda los trabajos que los estudiosos han dedicado a los diferentes episodios, y que se consignarán en cada momento. Deben destacarse los pioneros de E. M. Wilson [1961a y 1967], y muy especialmente la base de datos CLEMIT, que coordina Héctor Urzáiz y que es imprescindible para tratar una cuestión fundamental de la creación teatral en el Antiguo Régimen. Son 34 las obras del dramaturgo - 25 comedias y 9 autos sacramentales- que cuentan en ella con datos sobre censuras ${ }^{1}$. Casi la totalidad de la información sobre las obras calderonianas que ofrece este recurso corresponde a su dimensión escénica ${ }^{2}$, y una parte considerable la constituyen las censuras para la representación que constan en los manuscritos de las obras respectivas ${ }^{3}$, la mayoría de los cuales se custodian en la Biblioteca Nacional de España, depositaria de miles

\footnotetext{
http://buscador.clemit.es/. La cifra es de diciembre de 2018. Estos son los títulos de las 34 piezas con información sobre censura de diferente tipo y amplitud: El alcaide de sí mismo, El alcalde de Zalamea, El año santo de Roma, Basta callar, La desdicha de la voz, La devoción de la cruz, El día mayor de los días, El diablo mudo, La exaltación de la cruz, El galán fantasma, El gran príncipe de Fez, Guárdate del agua mansa, La humildad coronada, El José de las mujeres, Llamados y escogidos, El maestro de danzar, La más hidalga hermosura, El mayor encanto, amor, El mayor monstruo del mundo, El mejor amigo, el muerto, Las órdenes militares, El pastor Fido, Peor está que estaba, El postrer duelo de España, El príncipe constante, La protestación de la fe, La puente de Mantible, El purgatorio de San Patricio, Saber del mal y el bien, La segunda esposa, El secreto a voces, Los tres mayores prodigios, Troya abrasada y El Tuzani de la Alpujarra. Las fichas correspondientes no solo acogen los datos objetivos relacionados con cada pieza, con especial presencia de las aprobaciones que con vistas a la representación figuran en diferentes manuscritos, sino que también ofrecen las opiniones que en cada caso los estudiosos han podido dar sobre la existencia de censuras o autocensuras en distintas obras; y sin que falten las opiniones y aportaciones del coordinador del recurso Héctor Urzáiz. De no indicarse otra cosa, las citas de los textos de censura a lo largo de este trabajo se harán a partir de las fichas de la base de datos de CLEMIT.

2 La única excepción es El alcalde de Zalamea cuya información hace referencia a su llegada a las prensas.

3 Como la base de datos de CLEMIT intenta ser exhaustiva en el registro de manuscritos calderonianos que incluyen censuras, propongo la adición del autógrafo de Yerros de naturaleza, comedia en colaboración entre Antonio Coello y Pedro Calderón, que se conserva en la Biblioteca Nacional de España -BNE a partir de ahora- (MS/14778), donde tras los versos finales consta la remisión a censura firmada en Madrid, el 4 de mayo de 1634, y la licencia de representación de Jerónimo de Villanueva: "Esta comedia está escrita como de dos tan grandes ingenios puédese representar". Asimismo, podrían incorporarse las copias manuscritas del siglo XVIII del auto sacramental El nuevo palacio del Retiro, de las que se hablará más adelante.
} 
de testimonios en este formato, que hacen de ella, y con clara diferencia, la institución más importante del mundo en este tipo de materiales. Un fondo, además, que desde hace unos meses está prácticamente digitalizado en su totalidad y se puede consultar en línea en la Biblioteca Digital Hispánica ${ }^{4}$.

Las cuestiones susceptibles de censura y las formas de concretarse son múltiples, y de bastantes de ellas veremos algunos testimonios. Nos detendremos algo más, dentro de la rapidez general a la que obliga el espacio disponible, en los casos menos contemplados hasta ahora, mientras que sintetizaremos mucho en los ya tratados, con remisión a los trabajos previos. En esa sociedad española sacralizada donde los límites entre la religión y la política se confunden tienen una gran importancia los motivos doctrinales, y muy ligados a ellos los morales; el censor eclesiástico es figura indefectible a la hora de autorizar representaciones o publicaciones teatrales. Con ellos se relacionan algunos de los casos más interesantes y mejor estudiados, como el del auto sacramental de Las órdenes militares. Pero también hay censuras impuestas por razones políticas, y de eso Calderón ofrece un caso excepcional en el que estas se asociaron con circunstancias azarosas para dar al traste con un espectáculo sobre las proezas de Wallenstein que se exhibía en 1634 en el palacio del Buen Retiro. Asimismo, la censura podía provenir de la denuncia de personas concretas que se consideraran afectadas, como ocurrió en el también famoso caso de la sátira contra Fray Hortensio Paravicino de El príncipe constante.

Hay actuaciones censorias que suscitaron reacciones de aceptación o rectificación por parte del dramaturgo durante el tiempo en que aún estaba ligado a sus textos, como las que se han mencionado, pero también las hay cuando estos ya se habían desconectado de él y habían proseguido sus trayectorias durante los siglos XVII y XVIII ${ }^{5}$. Hay episodios, en fin, que cuentan con documentación fehaciente de la época, con textos explícitos emitidos por los órganos y personas competentes con vistas a la representación (presentes de manera especial en los manuscritos) o a la publicación impresa de los textos teatrales; en cambio, otros episodios apuntados son producto de deducciones o intuiciones de los estudiosos a partir de marcas en los soportes de transmisión o de diferencias entre versiones ${ }^{6}$.

\section{La autocensura en Calderón}

En las sociedades controladas, el primer sistema de intervención, y el más poderoso e infranqueable, es el de la autocensura. Los artistas, los poetas dramáticos en este caso, conocen muy bien los límites y los riesgos de sobrepasarlos, no solo por po-

4 En breve, ese extenso fondo de manuscritos teatrales que custodia la BNE, así como el resto de los manuscritos digitalizados de la institución, dispondrán de una herramienta extraordinaria para la búsqueda de censuras o de cualquier otro elemento que se quiera localizar, gracias al proyecto europeo de Recognition and Enrichment of Archival Documents (READ), que en España desarrolla el grupo Pattern Recognition and Human Language Technology (PRHLT), de la Universitat Politècnica de València (UPV). Para más información, ver el catálogo en línea de la exposición "Lope y el teatro del Siglo de Oro" celebrada en la BNE, del 28 de noviembre de 2018 al 17 de marzo de 2019.

5 Las censuras del siglo XVIII registradas en CLEMIT corresponden todas ellas a autos sacramentales: El año santo en Roma (1725), El día mayor de los días (1719 y 1733), El diablo mudo (1713 y 1751), El pastor Fido (1746) y La protestación de la fe (1752).

6 En CLEMIT son los casos de Basta callar, La devoción de la cruz, Guárdate del agua mansa, El maestro de danzar, La más hidalga hermosura, El mayor encanto, amor y El Tuzaní de la Alpujarra. 
nerse a la mira de órganos de control implacables, de los que pueden derivar daños en vidas y haciendas, sino por su adscripción laboral a instituciones, casas y señores, de los que reciben las contraprestaciones que les permiten tener medios de supervivencia y prestigio. En estas condiciones, es difícil imaginarse que los dramaturgos quisieran jugársela con críticas a personas o instituciones, o con opiniones comprometidas, y no importa lo razonables que fueran, sobre asuntos religiosos o políticos. Esta premisa de nuestra lógica actual no debe hacernos desistir en la indagación de los márgenes que tenían los artistas para dar consejos y avisos a sus señores en sus obras ${ }^{7}$.

La mayor parte de lo que Calderón dejó de decir por autocontrol queda fuera de nuestras posibilidades de averiguación. Pero sí que se podrían atender algunos aspectos concretos a través de la práctica de la reescritura, tan frecuente en él. Cada vez conocemos mejor esta faceta suya, gracias a los trabajos de especialistas como Ruano, Caamaño, Rodríguez-Gallego, etc. Las modificaciones a las que sometió algunos textos, pasado el tiempo, han podido llevarse a cabo por razones puramente dramáticas, pero también se han apuntado causas extra artísticas debidas a cambios en el contexto o en la percepción moral del escritor.

Hay indicios bastante claros de que la espontaneidad y el atrevimiento de algunas primeras propuestas fueron corregidos con posterioridad. Sirva de testimonio La vida es sueño, la obra más transcendental y considerada por espectadores y lectores, e incluso por el propio dramaturgo. Los trabajos de Ruano han identificado con nitidez y analizado sus dos versiones [1992 y 1994]; la primera de las cuales, según su teoría, habría sido escrita para su representación a cargo del autor de comedias Cristóbal de Avendaño, en una fecha anterior a 1630; la segunda la habría realizado en 1635 para incluirla como arranque de la Primera parte de sus comedias, con la que también daba inicio en 1636 la empresa de dejar memoria impresa de su teatro. Esta segunda versión reconduce la primera (o, por mejor decir, una de las copias con que había podido hacerse el poeta). Tras un análisis pormenorizado de las diferencias entre ambos textos, Ruano resume así los resultados: "la segunda [...] es una versión más acabada, más literaria, y más ortodoxa que la brillante, espontánea, original, atrevida y eminentemente teatral que Calderón compusiera en su juventud..." [1994: 20]. Aparte de lo que la segunda propone para corregir errores o para mejorar la caracterización de los personajes o la consistencia de la acción, es también evidente - aunque el investigador no lo diga con esta explicitud- que el Calderón más maduro habría sido censor del más joven:

Algunas variantes parecen tener como objetivo moderar ciertos excesos de la primera versión, o, al menos, lo que al más maduro Calderón pudieron parecer excesos. Se eliminan de la segunda versión ciertas lecturas que podrían considerarse excesivamente atrevidas, inapropiadas o inexactas. Entre ellas se encuentran algunas referencias a los cielos y al concepto de justicia divina. Sea por descuido o no, el hecho es que la primera versión deja entrever una deidad mucho más injusta que la de la segunda versión. Otros cambios de tipo ideológico tienen que ver con el concepto de ley natural o civil que conoce Segismundo [1994: 19]. 
A la autocensura en Calderón ha dedicado Ted Bergman [2002] un trabajo en el que analiza cuatro casos: El maestro de danzar, Guárdate del agua mansa, Yerros de naturaleza y La devoción de la cruz. Tres de ellas son producto de reescrituras sobre obras previas en las que la autocensura habría realizado algunos cambios y supresiones, según el estudioso, aunque no siempre parezcan claras las intenciones. En los cuatro casos se trataría de que el humor fuera menos grueso. En El maestro de danzar, reescritura de Dar tiempo al tiempo, se habrían limado las escenas entremesiles del gracioso Chacón. Un móvil semejante habrían tenido los arreglos que se producen en Guárdate del agua mansa sobre la versión anterior de El agua mansa: en este caso se trataría de conseguir que el figurón don Toribio Cuadradillos fuera menos grosero en su hacer y decir. En La devoción de la cruz, que reescribe La exaltación de la Cruz, habrían padecido el mismo proceso los versos satíricos del criado Gil.

Pero la autocensura no es algo que tengan que deducir siempre los estudiosos a partir de la existencia de pasajes recuadrados o del cotejo de reescrituras, sino que en alguna ocasión ofrece testimonios muy concretos ya detectados en su época por los propios censores. Es el caso del manuscrito de El gran príncipe de Fez, donde los responsables de aprobar la representación de la obra en septiembre de 1669 hacen suyos los atajos que el propio Calderón había realizado previamente en sus versos. El primero de ellos, Francisco de Avellaneda, se muestra especialmente hiperbólico en sus palabras de alabanza: "Señor he visto esta Comedia del Gran Príncipe de Fez de D. Pedro. Su Autor es tan riguroso Fiscal de su Papel que lo que va atajado de su mano le quita de aplausos a la discreción del auditorio". Mientras que, más comedido, Fermín de Sarasa y Arce sanciona: "lo que siento es que merece justissimamente la liçencia... y su autor el renombre de pri[ncipe] de la Comica composicion... Hagase obseruando lo atajado por el mismo autor" (BNE, MS/ Res. 100).

Son testimonios de consecuencias más o menos limitadas en lo textual las que hasta ahora se han apuntado. Sin embargo, Calderón pudo haber sido mucho más drástico en el ejercicio de la autocensura, si fuera cierto lo que afirma Bances Candamo en su Theatro de los theatros:

Don Pedro Calderón deseó mucho recoger la comedia De un castigo tres venganzas, que escriuió siendo mui mozo, porque vn Galán daua vna bofetada a su padre, y, con ser caso verdadero en Aragón y aberiguar después que era el Padre supuesto y no natural, y con hacerle morir, no obstante, en pena de la irreuerencia, con todo eso Don Pedro quería recoger la comedia por el horror que daua el escandaloso caso [1970: 35].

Estaríamos ante un caso de autocensura motivada por razones morales sobre una comedia cuyo título Bances confunde, pues es evidente que el episodio referido corresponde a Las tres justicias en una, obra que, efectivamente, y por la razón que sea, no aparece en las listas que el autor elaboró al final de su vida y que se conocen por los nombres de los que las encargaron, Carlos II (o de Maranón, que sirvió de intermediario) y Duque de Veragua. Está constatado que el Calderón octogenario que hacía balance de su producción en los años postreros no reconoció obras cuyos títulos habían cambiado o sus textos se habían deformado, pero ¿cuántas pudieron remover sus escrúpulos morales hasta llevarle a repudiarlas? En otras ocasiones he apuntado que esa podría ser la razón de que no reconociera como suya una comedia temprana titulada El perdón castiga más [2007 y 2008], en cuya trama, un tanto es- 
cabrosa, confluyen un intento de suicidio, violaciones y otros extremos de carácter moral que pudieron parecerle excesivos al viejo escritor ${ }^{8}$.

\section{Censuras de puestas en escena}

\subsection{En defensa de "la pureza de la fe y buenas costumbres"}

La expresión entrecomillada es del propio Calderón, quien la utilizó en la última de las aprobaciones de libros que firmó en 1681, y que se verá más adelante. Pero podría encontrarse exacta o muy parecida en cualquier contemporáneo suyo puesto en el trance de revisar alguna obra para su representación o impresión, cometido que tiene como objetivo principal impedir que nada pueda afectar negativamente a la fe y la moral católicas.

Como se adelantó, ocupa un puesto destacado en este grupo, y en el conjunto de episodios censorios en que se vio envuelto el dramaturgo, lo ocurrido con el auto sacramental de Las órdenes militares. Su motivación es de carácter teológico, e incide de lleno en la polémica sobre la Inmaculada Concepción de María, motivo de un largo e intenso debate entre dominicos y franciscanos, que ha dejado huella en muchos escritos literarios de la época, incluidos los teatrales.

J. M. Ruano de la Haza ha estudiado con detalle el caso de este auto de 1662 [Calderón 2005: 30-39], que aquí se resumirá. Después de ser exhibido ante las autoridades, fue denunciado al Consejo de la Suprema y General Inquisición, que lo prohibió por contener "graves impropiedades" antes de que pudiera ofrecerse públicamente. Como en otros autos sacramentales, Calderón había aprovechado un acontecimiento muy cercano en el tiempo como piedra angular sobre la que erigir la construcción alegórica de la pieza. En esta ocasión, se trataba de la promulgación, unos meses antes, de la bula Sollicitudo omnium ecclesiarum por el papa Alejandro VII, en la que apoyaba la devoción a la Inmaculada Concepción y prohibía discutir sobre ella. Dicha bula es utilizada por el poeta para respaldar que la Virgen había sido concebida sin pecado original, alegación fundamental para que Cristo supere las pruebas de pureza, que es en lo que consiste la traza del auto.

Según Ruano, el planteamiento de la Inquisición era impecable, dentro de las coordenadas de su tiempo y espacio, al objetar que ese escrito pontificio no podía ser tomado como aval de la Inmaculada Concepción. Por el contrario, sería Calderón, quien respondió a los calificadores del Santo Oficio con un memorial, el responsable de que el asunto se complicara, al reafirmarse en una postura nada flexible; que, por otra parte, constituye un expresivo testimonio de cómo en su madurez se sentía seguro al socaire de su prestigio y de la protección del poder [Calderón 2005: 34]. También estamos ante un testimonio más del sempiterno enfrentamiento entre lo verdadero en la literatura y en la realidad, en este caso de la teología. "Los califica-

8 De su repugnancia hacia los suicidios y de su afán de evitarlos hay dos posibles testimonios en sendos pasajes en que los estudiosos respectivos especulan que haya podido haber autocensura. El más antiguo se encuentra en su primera obra conservada, La selva confusa: E. Coenen, su editor, considera que la corrección de un pasaje al comienzo trata de evitar que pueda parecer un suicidio la caída al río del protagonista [Calderón 2011: 51-52]. El otro caso lo ha señalado T. Bergman [2002: 966-967] en el autógrafo de Yerros de naturaleza, comedia en colaboración con Coello. 
dores del Santo Oficio, preocupados por la ortodoxia religiosa - afirma Ruano-, eran incapaces de comprender que Calderón estaba escribiendo una obra de teatro y no un tratado de teología" [2005: 39].

El auto volvía a protagonizar otro episodio nueve años después, en septiembre de 1671. Al parecer, gracias a las instancias de Escamilla, el autor de comedias que lo había representado en 1662, se habría conseguido que Calderón rectificara lo suficiente sus planteamientos como para hacer posible su representación.

El escritor sexagenario que, con la seguridad que le daba su prestigio y sus apoyos, defendía su posición en 1662 frente a las objeciones de la Inquisición al auto de Las órdenes militares, no era el mismo, evidentemente, que quien casi treinta años antes, al remitir desde Pedrosa el auto de El nuevo palacio del Retiro en mayo de 1634, escribía una nota final en la que asumía de buena gana cualquier corrección que se le quisiera hacer, sin necesidad siquiera de consultárselo:

Si algo hubiera dicho en este auto con ignorancia, sea como no dicho, pidiendo la corrección de los yerros a la persona que fuere cometido, a quien suplico que por estar ausente y no poder yo hacer las enmiendas de sus advertencias, las haga él mismo. Pues cualquiera cosa que quitare o pusiere será lucir su representación y el afecto con que yo le he escrito, deseando servir al Consejo y a la Villa con aplaudir acciones suyas. En Pedrosa, a veinte y ocho de mayo de mil seiscientos y treinta y cuatro años. Don Pedro Calderón de la Barca9 .

La comedia de El José de las mujeres protagoniza otro de los casos bien conocidos de censura calderoniana, de la que se han ocupado E. M. Wilson [1961a], J. Aparicio [1999], J. Rubiera [2006 y 2011] y H. Urzáiz (CLEMIT). La firmó en 1679 el inquisidor Juan de Rueda y Cuevas en un manuscrito de 1659 que se conserva en la BNE (MS/ 16.548) e incide principalmente en la escena en que el demonio posee el cadáver de Aurelio: "se observe lo borrado y que el Demonio no entre en el cadáver, por ser herético y contra el Viejo y Nuevo Testamento". A J. Rubiera se deben las principales aclaraciones de la repercusión de dicha censura sobre el texto de la obra, y las posibles soluciones escénicas para este caso de complicada representación. H. Urzáiz clarifica aún más distintos aspectos relativos a las anotaciones del manuscrito y ofrece un buen estado de la cuestión.

La censura que afecta a El galán fantasma es tardía, hacía ya ocho años que había fallecido su autor, pero tiene el atractivo de confrontar a dos dramaturgos seguidores suyos, que manifiestan opiniones diferentes sobre un asunto menor pero que suscita reflexiones de cierto interés. Se encuentra en un manuscrito de la BNE (MS/15.672) con fecha de septiembre de 1689. Ahí puede leerse la objeción de Francisco Lanini a dos versos que, en su opinión, dan a entender algo que doctrinalmente es reprobable

9 He modernizado el texto a partir de la copia incluida en el manuscrito MS/16011 de la BNE, uno de los tres del siglo XVIII (los otros dos son: MS/15298 y MS/16279/4) que conserva la institución, y que también reproducen la aprobación de Agustín de Castro, la primera localizada en que un censor ensalza el trabajo de Calderón, algo que será habitual e irá creciendo en énfasis a medida que avance su trayectoria: "He visto con admiración este auto por orden de Vuestras Señorías. Está en la doctrina ajustado. Por la disposición tan dulce en los versos, tan elegante en los conceptos, tan agudo en el asunto, tan peregrino y tan felizmente conseguido el intento, dando el parabién a que tomando Vuestras Señorías esta comisión salga con acuerdo suyo cosa tan acertada por todos lados, de donde me prometo grandes aplausos en los interesados, que nunca me parecerán que lleguen a ser los que merece. En este Colegio Imperial de la Compañía de Jesús, a primero de junio de mil seiscientos y treinta y cuatro años. Agustín de Castro". 
como que "el alma dividida de la porción humana puede tener celos", y propone que no se digan. Aunque no es normal que un censor sea corregido por otro, en este caso se da. El replicante no podía ser otro que Juan de Vera Tassis, tan entregado siempre a la causa de Calderón. Para él, "es demasiado escrúpulo, pues mirando el concepto a otro sentido, es un hermoso hipérbole poético", que intenta explicar. Las palabras de Vera plantean cuestiones de cierta modernidad, movidas por un doble celo: el del editor, que hace notar los estragos que afectan al texto presentado por la compañía, que no respondía — señala - al que él mismo ha editado en la Segunda parte; y el celo de poeta que reclama — una vez más - que no se confunda la verdad de la poesía con la verdad de las cosas, precisión válida para este caso y para tantos otros de aquel tiempo y del nuestro. Y no es la única vez que se esgrime en las censuras calderonianas, como se pudo comprobar al tratar el caso de Las órdenes militares. En el caso que ahora nos ocupa, pudieron más la literatura, Vera Tassis y, sobre todo, Calderón, y los versos se autorizaron.

Entre las censuras por motivos de moralidad pueden citarse las que Juan Navarro de Espinosa, siempre tan puntilloso en estos asuntos, realizó sobre diferentes manuscritos de obras calderonianas. Uno de ellos es el autógrafo de Troya abrasada (BNE, MS/ Res. 78), comedia en colaboración entre Zabaleta y Calderón, fechado en 1644, donde se prohíben diferentes pasajes, algunos de los cuales - a juicio de E. M. Wilson [1961a: 169-171] — son plenamente merecedores de ello; lo que le sorprende - viene a afirmar con ironía - no es que se censuren sino que hayan podido escribirse pensando en decirlos sobre un escenario, destino obviamente mucho más restrictivo que el de la lectura. En opinión del experto en Calderón, estaríamos ante los pasajes más subidos de tono que ha leído en ninguna de las obras asociadas al nombre del dramaturgo; escritos, para mayor inconveniencia aún, en años de incremento del rigor de la censura. Por otro lado, la licencia pone el énfasis en algo que puede ser indicio de que en el escenario no siempre se respetara lo prohibido en el papel, aparte de que se dijeran cosas que nunca estuvieron en ese papel presentado para su control, como en el caso que veremos en seguida de El príncipe constante; Navarro de Espinosa advierte severamente de la obligación de atenerse a lo censurado: "Esta comedia se puede volver a representar, con apercibimiento que si algo de lo que en ella está borrado o reparado se dice, se castigará con graves penas al autor, al que dijere los versos y al apuntador, si no advirtiere lo notado en ella".

El mismo censor ve problemas morales en algunos puntos del manuscrito de $E l$ purgatorio de San Patricio que supervisó en 1652, los mismos - recuerda- que ya había denunciado en un examen de la obra en 1640: la descripción de las atrocidades cometidas en la mala vida de Ludovico Enio y especialmente el haber sacado a una monja del convento ${ }^{10}$.

También en 1640, Navarro de Espinosa había censurado en un manuscrito de El secreto a voces una alusión jocosa y un cuentecillo en que se hacen bromas con motivos religiosos.

\subsection{Las razones de estado de un dramaturgo de corte}

La política interfirió de una manera especial en la trayectoria teatral de Calderón, para impulsar su trabajo, inspirarlo, mediatizarlo o prohibirlo. Era obligado en un

10 A propósito del pasaje censurado y de la propia censura ver A. Regalado [1995: 566-567]. 
autor cuya larga vida artística estuvo principalmente orientada al servicio de una corte regia que explotaba el teatro para celebrar, exaltar y publicitar, objetivos todos ellos que exigían una escritura supervisada.

De los episodios que pueden considerarse en este apartado pienso que el más sorprendente es el que tuvo como figura central a Albrecht Wenzel Eusebius von Wallenstein, duque de Friedland, o de Frislán, como se le conocía en España. Las dos comedias protagonizadas por él vinieron a la postre a conformar una bilogía de próspera y adversa fortuna de características muy especiales: en primer lugar, porque no se concibió como tal desde el principio, por más que existiesen modelos en la época; $\mathrm{y}$, en segundo, porque ninguna de esas bilogías previas, como las dedicadas a Álvaro de Luna, Ruy López de Ávalos o Bernardo de Cabrera, tomaron como protagonistas a personajes de rabiosa actualidad. Wallenstein sí que lo era. Al frente de las tropas hispano-austriacas en una de las fases críticas de la Guerra de los Treinta Años, este noble bohemio era considerado por las monarquías coaligadas como una pieza clave para sus intereses bélicos, lo que llevó a la exaltación artística de su figura.

La política impulsada por el conde-duque de Olivares con el objetivo de potenciar la imagen del rey y de la monarquía había llevado a poner en acción a los profesionales de las diferentes artes para que construyeran palacios y coliseos, como los del Buen Retiro, pintaran cuadros o escribieran comedias celebrativas que llenaran esos espacios en los que debía brillar el Rey Planeta, Felipe IV. Un testimonio cabal y bien conocido de ese programa artístico es el que suscitó la toma de Breda en Flandes por las tropas españolas comandadas por Ambrosio de Espínola en 1625. No importaba que los episodios celebrados no fueran objetivamente relevantes, porque de lo que se trataba era de publicitar que sí y de exaltar el poderío militar y político español. Al servicio de esta causa concreta se pusieron los pinceles de Velázquez, que pintó su cuadro de La rendición de Breda o Las lanzas, y la pluma de Calderón, que compuso El sitio de Bredá.

Escribir con esos fines suponía acatar unas directrices que afectaban a la elección del tema, el perfil de los personajes, la selección de los episodios... Era un escribir condicionado del que el propio Calderón, en el final de la obra que se acaba de mencionar, deja constancia clara:

y con esto se da fin

al Sitio, donde no puede

mostrarse más quien ha escrito

obligado a tantas leyes.

No solo el dramaturgo se sentía "obligado a tantas leyes", los controles continuaban una vez realizado el encargo. Tenemos constancia de que el Consejo de Estado supervisaba los textos; así lo refieren diferentes testimonios que afectan a otros poe$\operatorname{tas}^{11} \mathrm{y}$ al propio Calderón. Muy oportuna al respecto es la información proporcionada por el embajador florentino Serrano en una carta de marzo de 1634 en la que precisamente da fe de la existencia de la primera comedia sobre Wallenstein, que había

11 Por documentos custodiados en el Archivo Mediceo de Florencia, de los que he tratado en otro momento, se sabe que Lope de Vega escribió una comedia perdida sobre la batalla de Lützen, con Wallenstein y Gustavo Adolfo como personajes, que fue prohibida por el susodicho Consejo por faltar al decoro de determinadas personas y por otras licencias poéticas. La misma fuente señala que el rey ordenó arreglarla a su ayudante Antonio Hurtado de Mendoza [Vega 2012: 42-43]. 
tenido ocasión de ver en el Buen Retiro, y de la que refiere algunas características y circunstancias, entre las que figura la que ahora interesa:

antes de ejecutarse en el teatro público, y como se ha hecho otras veces, porque trataba de príncipes vivos, a fin de que no se ofendiese ninguno o no se refiriese en estilo poético con cosa lejana de la verdad, fue examinada de nuevo por el Consejo de Estado, y, por último, aprobada. ${ }^{12}$

También la carta de Serrano refiere el deleite con que había visto la obra, cuya escritura atribuye a Calderón y Coello, en exaltación de "las proezas del duque de Frisland", por el acierto con que se presentaban los lances militares y se combinaba lo serio con lo cómico. Entre las cosas que le llamaron la atención está que "no nombra para bien ni para mal al Rey de Francia ni a francés alguno". Al diplomático italiano no podía pasársele por alto esta omisión cuando él y los receptores de su carta sabían de sobra que Francia era el gran problema subyacente en todo lo que tenía que ver con las hazañas bélicas del generalísimo bohemio. Era evidente que los dramaturgos escribían bajo directrices claras de carácter político, sino es que el silenciamiento de todo lo francés no fue labor posterior de la revisión del Consejo de Estado. Y no es la única vez que se evitan las referencias a Francia en obras de ese tiempo que tratan asuntos de política internacional, en los que el país vecino constituía el principal problema. Le ocurría otro tanto unos meses después al auto sacramental de El primer blasón del Austria, de atribución dudosa a Calderón, en que se celebra la victoria de Nördlingen ocurrida poco antes [Torres y Rull 1981].

Pero el proceso de autocensuras y censuras previas a la exhibición pública de la comedia quedó empalidecido al sobrevenir la prohibición fulminante de las representaciones en marzo de 1634. Se produjo de forma inmediata cuando el lento sistema postal de la época hizo llegar por fin a Madrid la noticia de que el héroe de la obra había muerto en Viena el 25 de febrero, a manos de miembros de su propio ejército a los que se les había encomendado la misión, por haber considerado que se entendía con Francia y que estaba dispuesto a traicionar los intereses hispano-austriacos. Esta circunstancia de la suspensión de representaciones la refirió años después Hieronymus Welsch en un libro de viajes publicado en 1658 en que trata de su estancia en Madrid en ese tiempo: "El sábado siguiente llegaron de Viena por el ordinario Avisos [...] Por las noticias de estas gacetas, la comedia mencionada no pudo representarse al domingo siguiente, tal y como estaba previsto, y las alabanzas se convirtieron en ignominia y menosprecio..."

Las muestras de "ignominia y menosprecio" surgirían espontáneamente de distintos puntos, pero es evidente que también las hubo dirigidas "oficialmente" desde el entorno de Olivares, conmocionado por el enorme chasco de haber estado celebrando a un traidor - y por encima de sus méritos, según se decía en los corrillos madrileños, tal como también refiere Wellsch. Desconozco qué influjo pudo tener ese entorno en que uno de los autos del Corpus de ese año, o del siguiente, con el título bien expresivo de La muerte de Frislán, del que es autor Álvaro Cubillo de Aragón, propusiera a Wallenstein como el Demonio. Lo que sí parece más que probable es que a instancias

12 El texto traducido es de Cotarelo [1924: 149-150].

13 El pasaje, que he traducido al español, lo dio a conocer Černy [1962: 177-179], quien estudió las características de la obra perdida. Ver también Sullivan [2000]. 
del mismo poder que había programado la comedia prohibida sobre Wallenstein se elaborase la titulada El prodigio de Alemania, cuyo texto se ha conservado en una suelta recuperada hace unos años, y que tiene la misión evidente de deconstruir al héroe de la primera y convertirlo en el pérfido traidor que merece la muerte al final de la obra.

No es momento ahora de extenderse en argumentos ofrecidos en otro lugar para plantear que Calderón debió de estar también detrás de este nuevo encargo, ejecutado de nuevo bajo la fórmula de la comedia en colaboración, y que posiblemente lo llevó a cabo otra vez con Coello ${ }^{14}$. Más allá de los ecos estilísticos calderonianos, hay indicios de diferente tipo que lo avalan, entre los que sobresalen las estrechas relaciones que tendría con la obra perdida, a juzgar por los datos que sobre esta proporciona el embajador Serrano. Se habría concebido como si fuera la segunda parte de una bilogía de doble fortuna, en cuyo inicio todavía se celebra al héroe de la batalla de Lützen (que se describe prolijamente en un romance muy calderoniano), para gradualmente ir mostrando que no es de fiar, hasta declararse su condición de traidor, que obliga a acabar con su vida. Ambas piezas se engranarían perfectamente en lo argumental; también, en el tono, con esa mezcla de lo serio y lo cómico que destacaba de la primera el diplomático florentino en su carta. Y otro detalle relevante más, producto de las directrices políticas que debieron de emanar del encargo: tampoco en ella se habla para nada de Francia, cuando es mucho más evidente aún que en la comedia que abría la bilogía que era la potencia que estaba detrás de la imputada traición de Wallenstein.

No es la única ocasión en que los intereses de la Corona en relación con Francia están detrás de episodios de censura de obras dramáticas. Son varios los casos que podrían alegarse que afectan a Lope ${ }^{15} \mathrm{y}$, al menos uno más, a Calderón, ocurrido bastantes años después. Razones políticas, de alta política, en relación con el país vecino pesaron para que, según los Avisos de Jerónimo de Barrionuevo, el propio rey decretara en 1656 la prohibición de la representación del auto de La protestación de la fe. En él se celebraba la conversión al catolicismo de la reina Cristina de Suecia ocurrida el año anterior, y que había conllevado su renuncia a una corona que precisamente ostentaba desde la muerte en la batalla de Lützen de su padre Gustavo II Adolfo, el respetado y temido antagonista de Wallenstein. Según Barrionuevo, la razón fue que "las cosas de esta señora no estaban en aquel primer estado que tuvieron al principio, cuya casa y servicio se compone ahora sólo de franceses" [1892-1893: II 423]. El asunto era considerado tan grave, que obligaba a su suspensión a primeros de junio, cuando ya estaba escrito el auto y apenas había margen para sustituirlo. Pero el prestigio de Calderón hacía que el rey confiase en que esto sería posible, tal como recoge también el aviso: "y aunque esté tan adelante el tiempo, yo fío del ingenio de D. Pedro Calderón que hará otro luego para que no haya falta en el festejo de tan gran día".

\subsection{Por alusiones personales}

Este apartado solo registra un caso, pero afecta a uno de los títulos más relevantes del escritor, aunque no sea de los que hoy puedan verse con facilidad en las carteleras:

14 Sobre el hallazgo de la obra, sus problemas textuales y de autoría, y su contenido ver Vega [2001]. La presencia de marcas de estilo calderonianas en pasajes de las tres jornadas parece apuntar que sobre él recayeron los trabajos de coordinación, que se llevarían a cabo con la urgencia que exigían las circunstancias.

15 Extraordinario es el caso de El blasón de los Chaves de Villaba, por la peculiar solución que se le dio, consistente en cambiar "Francia" y "francés" por "Albania" y "albanés", sin importar las alteraciones de la métrica y que todos conocían de sobra la historia que se quería camuflar [Vega 2012: 47-48]. 
El príncipe constante, la obra que quizá más ha hecho por la valoración internacional de Calderón, merced a los juicios de personalidades de la talla de Goethe, que la consideraba capaz de recuperar la poesía occidental si llegara a perderse, o de Grotowvski, que en 1968 llevaba a cabo con ella uno de los montajes de referencia del teatro actual. Más de cuatro siglo antes, sus primeras representaciones en la primavera de 1628 habían dado lugar a uno de los casos más famosos de la censura teatral en el siglo XVII, por los personajes implicados, Calderón y el celebrado predicador Fray Hortensio Paravicino, y por lo que da a entender sobre los límites de la censura, capaz de controlar más o menos bien lo que por escrito se presentaba al censor, pero no tanto lo que los representantes decían sobre el escenario ${ }^{16}$. También el episodio resulta atractivo por su comicidad, derivada no solo de los versos que no debió decir el gracioso de Calderón sobre el tablado sino también por lo que Paravicino dijo en su memorial de queja, en el que afortunadamente además incluyó los versos de marras, que se hubieran perdido para siempre de no ser as ${ }^{17}$. En ellos Brito satiriza el estilo pomposo del predicador al maldecir el agua de la que sale en la primera jornada:

$\begin{array}{ll}\text { PRÍNCIPE } & \text { ¿Qué es eso? } \\ \text { BRITO } & \text { Una oración se fragua } \\ & \text { fúnebre, que es sermón de Berbería: } \\ & \text { panegírico es que digo al agua } \\ & \text { y en emponomio horténsico me quejo, } \\ \text { porque este enojo, desde que se fragua } \\ \text { con ella el vino, me quedó, y ya es viejo. }\end{array}$

La queja de Paravicino no conseguiría la prisión del dramaturgo como solicitaba, ya que, al parecer, esos versos se siguieron recitando en las representaciones, y se dice que el propio rey llegó a oírlos y celebrarlos con sonrisas.

Las hipérboles habituales de la oratoria sagrada barroca de la que Fray Hortensio es paradigma afectan los argumentos, "pretendiendo elevar - como dice Urzáiz (CLEMIT) - las mofas hacia su persona a la categoría de ataque blasfemo contra la religión y la monarquía". Unas mofas, por otra parte, que el barroquismo también evidente de Calderón no hacía fáciles de comprender, como con cierta sorna acusa el cardenal Trejo en el parecer que acompaña al memorial: "aunque yo no soy poeta, [la copla] está tan violentada en el lenguaje que apenas se deja entender".

\section{Censuras de impresos teatrales}

\subsection{Las aprobaciones de las partes de Calderón}

A pesar de que el género dramático tiene su destino principal en los escenarios, la Comedia Nueva gozó de una gran acogida en las imprentas y librerías, en las que

16 A pesar de las amenazas con que, en ocasiones, advierten sobre su obligado cumplimiento, como en el caso de Troya abrasada, que vimos más arriba.

17 El memorial fue dado a conocer por Wilson [1961b]. Recientemente Isabel Hernando [2017-2018] ha editado con precisión y analizado esta demanda que Paravicino presentó al Consejo de Castilla, a la que acompaña el parecer del cardenal Trejo. 
Calderón descolló como ningún otro, hasta convertirse en uno de los escritores más leídos del Siglo de Oro. Son centenares las ediciones de sus obras que vieron la luz, especialmente de sus comedias. Sin embargo, la mayoría de esos impresos que las acogieron respondían al formato de sueltas, cuya adscripción al universo del pliego suelto les permitía — aun contra la legalidad - prescindir de aprobaciones. Por el contrario, es raro que no las lleven cuando se publican en libros, en volúmenes conocidos como partes, en los que se suelen juntar doce. Las obras del dramaturgo aparecieron con asiduidad en las colecciones que agrupaban las de varios autores a lo largo del siglo, pero sus aprobaciones no generaron menciones específicas a su persona o labor. Sí que lo hicieron - y son las que interesa ahora contemplarlas de su colección particular, compuesta por nueve partes de comedias —diez, en realidad, ya que de la Quinta hay dos propuestas bien diferentes- y una de autos sacramentales ${ }^{18}$.

La idea que el público profano suele tener de una literatura del siglo XVII férreamente controlada, a la que para publicarse se exigía pasar por los filtros de las aprobaciones civil y eclesiástica, se disipa un tanto cuando entramos en contacto directo con los propios libros y nos percatamos de que en la práctica estas censuras, cuyos textos debían imprimirse en los preliminares, con frecuencia, lejos de reflejar rigor doctrinal, moralista o político se convierten en apasionadas alabanzas de las bondades del autor y la obra que preceden. Se produce lo que algunos como el Padre Juan Ignacio Castroverde expresa lisa y llanamente al inicio de la aprobación del único libro de autos sacramentales que publicó Calderón: que "los materiales que se buscan para su censura sirven para su elogio". Se diría que la obligación de obtener las aprobaciones oficiales se compensaba con el margen que el sistema dejaba para conseguir que estas no cayeran en manos de censores feroces y menos aún de los enemigos del teatro, que no eran pocos, y sí de los partidarios, que con regularidad también lo solían ser del ingenio cuyas obras aprobaban ${ }^{19}$. De esto pueden dar buena cuenta las partes de Calderón.

Su primer encuentro con la censura se produjo en 1635 cuando se gestionaba la edición de la Primera parte de sus comedias, aparecida en 1636 (Madrid, María de Quiñones-Pedro Coello y Manuel López ${ }^{20}$, poco después de que fuera de nuevo posible publicar obras de ficción en el reino de Castilla tras diez años de suspensión de licencias. Para entonces el escritor disponía ya de tantas comedias como para haber completado varias partes, y de un prestigio indiscutible, que aún se afirmaba más con la muerte de Lope de Vega ese mismo año. La reactivación editorial que había impulsado desde el primer momento a otros autores teatrales como Tirso, Montalbán o el mismo Lope, le animó a buscar el refrendo de su prestigio en este cauce abierto más de treinta años antes para la Comedia Nueva. El éxito literario cada vez más estaba ligado a los libros impresos, sin excluir el teatro. Eso parecen buscar sus dos

18 Para abordar las aprobaciones de los impresos teatrales es de consulta imprescindible la web de Les Idées du Theâtre. IDT (http://www.idt.paris-sorbonne.fr/), donde se pueden consultar los resultados de un ambicioso proyecto internacional sobre los paratextos de las ediciones teatrales en Francia, España e Italia. De los calderonianos se han encargado Tatiana Alvarado Teodorika, Juan Carlos Garrot, Carine Herzig y Fabrice Quero. En las citas sigo estas ediciones con los textos modernizados.

19 A este propósito dice E. M. Wilson con un guiño irónico hacia el tiempo presente (o cercano, al menos): “el poder de la amistad española era tan eficaz en aquel siglo como en el de hoy. Los que publicaron tomos de comedias tenían sus trucos para no dejarlos caer en manos de los enemigos de las comedias, cuando era cuestión de conseguir las dos aprobaciones de las autoridades eclesiástica y civil" [1967: 162].

20 Solo haremos mención de las primeras ediciones de las partes respectivas. 
primeras partes publicadas al cuidado de su hermano José, pero con Pedro detrás, como prueba que su nombre figure en los privilegios de ambos volúmenes. Su interés por buscar con la publicación la ratificación de su ascenso literario y social se ve aún más claro en la Segunda parte (Madrid, María de Quiñones, 1637), cuya portada luce su recién concedida condición de caballero de la orden de Santiago, a la que se había hecho merecedor por sus servicios de letras a la corona.

Ya desde la Primera parte tenemos constancia de ese prestigio, a pesar de la brevedad de las aprobaciones y del despliegue de frases hechas como la de "no tener cosa contra nuestra santa fe ni buenas costumbres" - que escribe Juan Bautista de Sosa- o "no hallar cosa disonante a la verdad católica de nuestra sagrada religión ni peligrosa a las costumbres" - en el decir de Joseph de Valdivieso. Este, como es frecuente en tantas aprobaciones, reúne la condición de colega del censurado, $\mathrm{y}$, como también es lo habitual, aprovechó para ensalzarlo. No obstante, el énfasis de Valdivieso se separa de lo que es el trato positivo normal entre compañeros de lances teatrales y se convierte en una prueba del prestigio de que ya gozaba el autor de esa docena de piezas encabezadas por La vida es sueño:

En estas Comedias que me mandó ver V. A. y que escribió don Pedro Calderón de la Barca, cuyo ingenio es de los de la primera clase en la novedad de las trazas, en lo ingenioso de los conceptos, en lo culto de las voces, y en lo sazonado de los chistes, sin que haya ninguna que no encierre mucha doctrina moral para la reformación, muchos avisos para los riesgos, muchos escarmientos para la juventud, muchos desengaños para los incautos y muchas sales para los señores, y basta su nombre para su mayor aprobación, pues en los teatros se las ha merecido de justicia.

Los mismos nombres aparecen en las aprobaciones de su Segunda parte, que firman en la primavera de 1637. La de Joseph de Valdivielso se mantiene en el mismo tono encomiástico, añadiendo un apunte sobre el éxito en los teatros y este remate: "El ingenio del Autor es tan conocido que sería desacuerdo intentar sus alabanzas, por ser superior a las mayores y todas se dicen en diciendo que es de don Pedro Calderón".

La Tercera parte no vio la luz hasta casi treinta años después, en 1664 (Madrid, Domingo García Morrás-Domingo Palacio y Villegas), y al margen de las decisiones del autor. Su fama ya era indiscutible y las aprobaciones subían aún más el calor de la alabanza. Es más, anunciaban ya lo que se habría de producir a la muerte del dramaturgo con la aprobación que el Padre Guerra firmaría en los preliminares de la Verdadera quinta parte (1682), cuando definitivamente Calderón fue tomado como arma poderosa en defensa del teatro. Manuel Mollinedo y Angulo hace mención de esa preeminencia incluso más allá de nuestras fronteras, ante lo que considera imposible censurar nada:

Siendo el autor tan estimado y aplaudido, no solo en nuestra España sino en las más naciones del mundo, habiendo traducido sus obras en su idioma, cualquiera aprobación y censura mía quedará muy corta; solo sé decir que continuamente le quisiera estar oyendo, porque la eficacia en sus razones y lenguaje en el hablar excede a toda ponderación. 
Para Tomás de Oña, responsable de la aprobación civil, "bien merece Don Pedro Calderón entre los españoles la antonomasia, que Homero entre los griegos y Virgilio entre los latinos": así inicia un texto que sobrepasa en espacio a cualquiera de los vistos hasta este momento, y que prosigue con una exaltación encendida del teatro: "En su censura no halló que hacer mi obediencia, porque el libro traía consigo su aprobación, gracias a tan dorado siglo, en que ha llegado el arte poética a toda su perfección, logrando la utilidad en el deleite, y la verdad de los morales dogmas en el apacible halago de los sentidos". A esta defensa dedica una prosa rebuscada en fondo y forma, centrada fundamentalmente en la poesía, que llega a asociar a la sagrada.

Bastantes años vuelven a transcurrir hasta que vio la luz la Cuarta parte (Madrid, Joseph Fernández de Buendía-Antonio de la Fuente, 1672), cuya publicación —si hacemos caso a lo que el poeta afirma en su dedicatoria "a un amigo ausente"- es fruto de un acuerdo entre el escritor y su compilador. En esa misma dedicatoria se alista una cuarentena larga de títulos que circulan a su nombre sin que se deban a su pluma (aunque no en todos los casos sea cierto). Si las aprobaciones eclesiásticas son escuetas y frías, para lo acostumbrado hasta este momento, la de Francisco de Avellaneda dispara sus elogios a la mayor altura, superando la que ya le hemos leído a este mismo censor e ingenio dramático en sus licencias de representación en diferentes manuscritos:

he visto un libro de doce comedias de Don Pedro Calderón de la Barca, Cuarta Parte dellas, que se da a la estampa, para que califiquen las mejores observaciones de los ojos cuantos discretos primores han logrado los oídos, en tantos repetidos aciertos, como vocean inmortales sus aplausos. Díganlo sin emulación todas las naciones, pues en sus dialectos traducidas las veneran [...] No es osadía cariñosa, por las veneraciones que le tributo, verdad sí, mas apoyada en todo el resto de tantas repetidas calificaciones que la ilustran.

Un volumen titulado Quinta parte de comedias de Don Pedro Calderón apareció en 1677 totalmente ajeno a la voluntad y control del dramaturgo, quien en el prólogo de su libro de Autos sacramentales, alegóricos y historiales de ese mismo año manifestó su contrariedad y denunció sus "falsedades": "haberse impreso en Madrid y tener puesta su impresión en Barcelona, no tener licencia, ni remisión, ni del Vicario ni del Consejo, ni aprobación de persona conocida [...] De diez comedias que contiene, no ser las cuatro mías". Efectivamente, como ha averiguado D. W. Cruickshank [1973], esa edición de Barcelona (que dice salida del taller de Antonio la Caballería) en realidad se publicó en Madrid y de ella salió una segunda con pie de imprenta madrileño. En lo que Calderón no lleva razón es en que cuatro comedias no sean suyas (y, menos, en que no lo sean ni cuatro, que también se puede entender así): hoy es prácticamente seguro que son todas suyas excepto El rey don Pedro en Madrid e Infanzón de Illescas.

El falso volumen solo lleva una aprobación, con todos los indicios de ser falsa (entre otros, la fórmula utilizada, que parece copiada de la Parte veinte y cinco de Comedias escogidas de 1671), y en la que se dicen falsedades (como que el libro tiene doce comedias cuando en realidad solo son diez). Está a nombre de Fray Jaime Castella, con fecha de 10 de julio de 1676. Por primera y única vez, nos encontramos ante unos preliminares que no dedican ni una sola alabanza a Calderón.

Efectivamente, también en 1677 aparecía el último volumen publicado en vida del escritor con obras exclusivamente suyas, el de Autos sacramentales, alegóricos y 
historiales (Madrid, Imprenta Imperial-Joseph Fernández de Buendía), que a la vez es el único en el que el dramaturgo se responsabiliza abiertamente de su edición, por el motivo que se explica en la dedicatoria:

porque siendo, como son, tan escrupulosos sus asuntos, que por un término errado, o por la pluma, o por la prensa, puede pasar de lo sensible del ingenio a lo intolerable de la reputación, me ha movido (mejor dijera me ha forzado) a que ya que hayan de salir, salgan por lo menos corregidos y cabales, que para defectos bastan los míos, sin que entren a la parte los ajenos.

En esa misma dedicatoria, que titula muy intencionadamente "Al lector. Anticipadas disculpas a las objeciones que pueden ofrecerse a la impresión destos autos", se preocupa en especial de dos cuestiones: de justificar la existencia de reiteraciones, a las que obliga el que todas las piezas traten sobre un mismo asunto; $y$ de advertir que la letra sola, sin la música ni las tramoyas, es incapaz de dar cuenta del espectáculo.

También el volumen de 1677 supone la culminación de la tendencia a aprovechar las aprobaciones para elogiar al autor aún vivo. Asimismo, son las más extensas. La del Padre Juan Ignacio Castroverde apunta reflexiones interesantes, desde ese tono general de alabanza. Le responsabiliza de "la admirable forma que hoy tienen" los autos. Sus cualidades dan "justos motivos para que le miremos por casi divino, pues es verdad que sus escritos no le contienen en los términos de humano". Y prosigue:

La admirable distribución con que elevó la comedia a ciencia en perfecto silogismo, proponiendo, dificultando, y resolviendo, no sólo adelantó, sino mudó la forma con que escribieron Terencio y Plauto en los antiguos, Petrarca en lo más moderno, y los españoles en nuestro siglo.

El tono panegírico no resta valor a la agudeza de algunos de sus comentarios, que se adelantan a las apreciaciones de críticos posteriores; como cuando valora su capacidad de convertir en teatro conceptos tan abstractos: "hacer los conceptos de Cristo sacramentado representables, y explicarlos con la viva demonstración de alegorías, entendiendo una cosa por la significación de otra, son invenciones del entendimiento, cuya virtud no es otra que saber hallar".

También el doctor don Juan Mateo Lozano en su aprobación se pasa "a panegirista de censor", por decirlo con sus propias palabras. Pero tampoco faltan perspicaces y compendiosas apreciaciones:

Apenas hay suceso que haga viso a este asunto, así en divinas como en humanas letras, de que no haya valídose su idea en representaciones visibles para sus mayores obsequios, observando en cada uno el rigor de la letra para lo textual, la consecuencia en las alegorías, la similitud en las metáforas, la puntualidad en las traducciones...

En 1682, al año siguiente de la muerte de Calderón, Juan de Vera Tassis iniciaba su titánica tarea de proseguir la publicación de las partes del escritor ${ }^{21}$, que habrán

21 Se trató, sin duda, de un trabajo enorme y de empeño fundamentalmente personal, para el que no debió de contar con demasiada ayuda de Calderón, a pesar de que se consideraba su amigo, y como tal —"íntimo amigo"— le nombra Juan Baños de Velasco en el arranque de su aprobación al primero de los volúmenes. Independientemente 
de salir de la imprenta madrileña de Francisco Sanz en los diez años sucesivos. Recuperó el número cinco para la primera que sacó a la luz, y desautorizó con claridad la publicada en 1677 desde el propio título de Verdadera quinta parte. Seguirían la Sexta (1683), la Séptima (1683) y la Octava (1684); y antes de publicar la Novena y última en 1691, verían la estampa las ediciones de las cuatro partes que se habían impreso en vida de Calderón.

De la Quinta a la Novena parte, cuentan con una de las aprobaciones más célebres y extensas de los libros de ficción en el Siglo de Oro: la de Fray Manuel Guerra y Ribera, catedrático de Filosofía de la Universidad de Salamanca y predicador de Su Majestad. Si el texto íntegro se incluye en los preliminares de la Quinta y Sexta, los de la Séptima a la Novena remiten a ella ${ }^{22}$. El Padre Guerra aprovecha su espacio, que toma con una generosidad sin parangón en este tipo de paratextos - hasta 47 páginas-, para ensalzar al dramaturgo y utilizarlo como antídoto contra los enemigos del teatro, que habían arreciado sus ataques en los últimos tiempos.

Con el argumento de que solo se puede aprobar algo si es legítimo el género al que pertenece - "mi escrúpulo es que esta aprobación particular pende de la universal, porque no podrá ser una comedia particular buena, si la Comedia en común es mala"-, dedica la mayor parte de su escrito a su defensa, hasta convertirse en un verdadero tratado sobre ella, que, a juicio de E. M. Wilson, constituye junto con el Theatro de los theatros de Bances Candamo las dos obras más relevantes de la crítica teatral de la época de los Habsburgos, escritas ambas en los veinte años finales de la centuria [1967: 170].

La defensa del Padre Guerra entró de lleno en un momento muy delicado de la larga controversia por la licitud moral del teatro, y se erigió en uno de sus principales reactivos, a juzgar por el número de escritos en favor y en contra a los que dio lugar en los dos años siguientes, que sobrepasarían la veintena [Herzig 2008] $]^{23}$.

Guerra da nuevos bríos a los argumentos ya utilizados por los defensores del teatro aurisecular desde los primeros escarceos del largo debate. En primer lugar, que aquel contra el que arremetieron los Padres de la Iglesia, y que había pertrechado de argumentos a sus enemigos, no tenía nada que ver con el que se veía en España: "Con sinceridad pregunto si en el rostro feo que he pintado de las comedias antiguas - a lo que efectivamente ha dedicado bastantes páginas- han hallado alguna facción de las nuestras". Solo se parecerían en el vocablo. Interesante - por lo que tiene de perspectiva de época, hoy que la tipología genérica es objeto de investigación preferente- es el punto en que divide a las comedias españolas en tres clases: "de santos, de historia y de amor, que llama el vulgo de capa y espada". Y apunta los beneficios que de ellas se derivan:

Si son de santos, el ejemplo mueve, los milagros se imprimen, la devoción se extiende [...] Si son historiales, los avisos doctrinan, los sucesos escarmientan, los

del grado de amistad, parece claro que no le proporcionó materiales ni informaciones especiales, como en otra ocasión he apuntado [Vega 2013: 116-118]. Lo que es evidente también es el derroche de trabajo y de olfato que cabe agradecerle a Vera a la hora de identificar comedias, seleccionar los mejores materiales, cotejarlos: en definitiva, un trabajo inusual para los hábitos editores de la época, sobre todo cuando se trataba de obras de ficción.

22 Estaríamos ante una muestra más de la laxitud de las aprobaciones. Si es posible aceptar que el Padre Guerra vio en 1682 los textos de la Quinta a la Octava partes, hay indicios claros de que no pudo conocer los de la Novena en su integridad, ya que a Vera Tassis le costó completarla, lográndolo al fin nueve años después en 1991, motivo por el que antepuso las reediciones de la Primera a la Cuarta.

23 Ver también Idées du Téâtre, http://www.idt.paris-sorbonne.fr/notice.php?id=90. 
desengaños atemorizan. Si son de pasos amatorios (que son las menos morales), están tratados con tal honestidad que ni se permite indecencia ligera en los afectos, ni voz menos pura que no saliese castigada a silbos.

"La Comedia es indiferente en lo cristiano [...], conveniente en lo político": al Padre Guerra le interesa aclarar que Santo Tomás, cuyo pensamiento considera que tergiversan quienes se oponen al teatro, "no condena las comedias, sino las comedias malas", al tiempo que defiende la conveniencia para la vida humana de la eutrapelia, es decir de una "recreación moderada".

Otro de los pasajes interesantes es el dedicado a los toros: "Días ha que ando batallando en mi mente con una admiración, y es ver que las mismas plumas que impugnan tan agriamente las comedias no censuren los toros". Con una dialéctica impecable se aprovecha de la fiesta taurina para mostrar, por contraste, las bondades de la teatral:

Estas bien admitidas fiestas no tienen, para mí, pretexto que las disculpe [...]. Una comedia puede ser del Sacramento, de la Virgen Santísima o de santo, puede excitar y excita tal vez llanto, devoción y, en alguno, contrición; de una fiesta de toros, ¿quién ha salido arrepentido, si no es del cansancio? Una comedia historial tiene muchas advertencias morales; una fiesta de toros no tiene más, en todo su teatro, que irracionalidad todo. Una comedia puede ser ocasión de bien y, en la contraria, sentencia de mal; una fiesta de toros está precisada a ser ocasión de mal, y no haber mucho mal se tiene, en la fiesta, por mucho bien.

Y llega el momento de que la aprobación del Padre Guerra se ocupe de las comedias de Don Pedro ${ }^{24}$, el principal valedor en la defensa del teatro: "Sin agravio de tantos insignes poetas como han ilustrado y ilustran el teatro del mundo y de esta Corte, me han de permitir que diga que sólo nuestro don Pedro Calderón bastaba para haber calificado la Comedia y limpiado de todo escrúpulo el teatro". Aunque hiperbólico en sus alabanzas, no anda desencaminado al apuntar cualidades que hoy le reconocen los estudiosos. No obstante, con lo que más en desacuerdo se puede estar es con su vehemente proclamación de la originalidad del dramaturgo: "a ninguno imitó. Nació para maestro y no discípulo, rompió senda nueva al Parnaso, sin guía escaló su cumbre. Ésta es para mí la justa admiración, porque bien saben los eruditos que han sido rarísimos, en los siglos, los inventores". Hoy tenemos claro que Calderón es uno de los dos o tres cultivadores más egregios de una fórmula que explotaron muchos y que se gestó durante décadas de experimentación, con Lope como principal referente y promotor; de igual manera, sabemos bien de su proclividad a la reescritura, con geniales resultados, eso sí; y que también en esta faceta Lope, entre otros, estuvo sobre su mesa.

La Quinta y Sexta partes incluyen también el texto de la aprobación de Juan Baños de Velasco y Ácebedo, mientras que los de la Séptima a la Novena remiten a ella. El "censor" se confiesa amigo de su editor Vera Tassis, al tiempo que ensalza a Calderón y al Padre Guerra: "uno y otro solo me deja lugar para la admiración, y no voz para

24 No sin antes confesar sin tapujos — por si quedaba alguna duda sobre las pretensiones de imparcialidad en la aprobaciones - que es "íntimo dueño mío por obligación contraída al favor singular de haber admitido ser informante en mis pruebas de predicador de su Majestad". 
la censura"; algo que ha estado operativo en la práctica totalidad de los preliminares vistos. Lo que más sorprende es la referencia que hace al principio a sus "libros de comedias y sainetes varios" que ha recogido Vera Tassis. La mención a una supuesta recopilación de piezas breves más parece despiste involuntario del aprobador (que a lo mejor tampoco llegó a ver la de comedias, aunque las aprobara) que testimonio de su existencia real, nunca mencionada por Calderón ni por Vera Tassis.

\subsection{Calderón, censor}

A pesar de lo prometedor del título del apartado, este se ocupará solo de una faceta muy concreta del dramaturgo, la de autor de aprobaciones para los libros de otros. Ni hay espacio ni es el momento de plantear cómo utilizó su teatro para censurar comportamientos y actitudes de personas y grupos pertenecientes a ese poder que, a su vez, le controlaba a él y a los artistas como él. Una faceta que ha recibido sugerentes propuestas por parte de los estudiosos, que han visto esta actitud ya desde sus primeros compases ${ }^{25}$. Son asuntos tan apasionantes como complicados de abordar, en los que, de acuerdo con lo que se apuntaba al principio, hay que armonizar las obligaciones que hacia el poder que les sustentaba tenían los artistas con el margen de libertad para decir cosas que precisamente por ser artistas se les aceptaba -y hasta se esperaba de ellos- por parte del poder.

Como escritor integrado en el tejido de creación y control de la España del Siglo de Oro, a Calderón le tocó también emitir aprobaciones, actividad en la que no parece que se prodigara mucho, a juzgar por su larga trayectoria y la cifra de las localizadas, diecisiete, todas ellas correspondientes a libros impresos ${ }^{26}$, en ningún caso, que conozca, a puestas en escena. Aquí comentaremos únicamente las que corresponden a publicaciones con un mayor componente literario y en especial las teatrales.

A esta condición obedece el primer libro que lleva una aprobación suya del que tenemos noticia, la Quinta parte de comedias del maestro Tirso de Molina (Madrid, Imprenta Real-Gabriel de León, 1636). Está fechada el 16 de julio de 1635, y en ella se muestra bastante comedido y convencional, aunque no deje de reconocer el magisterio del veterano poeta dramático:

hay en ellas mucha erudición y ejemplar doctrina por la moralidad que tienen, encerrada en su honesto y apacible entretenimiento, efectos todos del ingenio de su autor, que con tantas muestras de ciencia, virtud y religión ha dado que aprender a los que más deseamos imitarle.

Parece claro que manifiesta menos entusiasmo que el que había mostrado Joseph de Valdivielso al aprobar ese mismo año su Primera parte; lo que quizá sea fruto de ese afán competidor que el más destacado de los "pájaros nuevos" podía experimentar hacia sus padres teatrales, tal como asomaba en ocasiones en su relación con Lope.

25 Por ejemplo, en Amor, honor y poder, de la que consta que fue representada en 1623, lo que hace de ella la segunda conservada tras La selva confusa, D. W. Cruickshank ha querido ver una crítica a la conducta extraconyugal del rey Felipe IV [2002: 95-96].

26 E. M. Wilson registra siete [1963], a las que se suman otras nueve en el apartado que a ellas se dedica en Reichenberger [1979: 703-706]. En CLEMIT se da noticia de una más. 
El 20 de noviembre de 1650 firmaba la aprobación que va al frente del libro de Jerónimo de Cáncer, Obras varias (Madrid, Díaz de la Carrera, 1651), que contiene fundamentalmente poemas de diferente tipo, pero que al final incorpora la comedia burlesca La muerte de Valdovinos. Aunque el prestigio del autor le avala - señala Calderón-, tras la lectura de los textos no encuentra "inconveniente que reparar; antes bien mucho que agradecer al estilo, en quien se hallan usados con agudeza y donaire los primores de la lengua castellana".

En 1652 se iniciaba la colección conocida como Comedias escogidas (o Nuevas escogidas), la serie de partes de comedias más extensa de cuantas vieron la luz en el siglo XVII, y que de alguna manera recogía el relevo de la denominada de Diferentes autores. Se abría con una Primera parte (Madrid, Domingo García y Morrás-Juan de San Vicente, 1652) en la que como reclamo se incluían hasta cinco comedias del que era indiscutiblemente el dramaturgo más celebrado desde hacía lustros, don Pedro Calderón de la Barca. Hasta la distribución de sus textos en el volumen da idea de ese interés en destacar su presencia. Lo sorprendente es que sea suya una de las aprobaciones. Si es curioso el régimen de reciprocidades censoras de la época en que los escritores se autorizan sus obras entre sí, aquí se llega al exceso de hacerlo a sí mismo [Bouza 2012: 77-78]. Bien es verdad que el trance lo afronta el aprobador aprobado con el texto más escueto y tópico de los registrados: "no habiendo en ellas reparado cosa alguna que contradiga a nuestra santa fe y buenas costumbres, podrán imprimirse". Es, por lo extremado, un testimonio bien expresivo de las peculiaridades del sistema. De todas formas, este proceder no podemos considerarlo normal, ni desde la perspectiva de la época, como indica el que se intentara evitar en otro de los volúmenes de la misma colección en que también aparecía propuesto como aprobador, la Oncena parte (Madrid, Gregorio-Rodríguez-Juan de San Vicente, 1659), que incluía tres comedias suyas [Bouza 2012: 79]. No obstante, el problema se arregló solo a medias, ya que su sustituto, Antonio de Solís, era también responsable de una de las obras del libro, Triunfos de amor y fortuna.

Ese mismo año de 1652, el 24 de julio, firmaba una de las licencias de La vida y hechos de Estebanillo González, hombre de buen humor (Madrid, Gregorio Rodríguez, 1652), que Antonio Regalado califica de "novela abundante en crueldades y atrocidades y en humor descarnado y macabro" [1995: 567], pero que Calderón no encuentra censurables: "a mi juicio, no tiene inconveniente que disuene a la pureza de la fe y decoro de las costumbres, porque no toca materia que exceda al ocioso divertimiento de quien le leyere". Lo que al parecer del estudioso contrasta con las pegas que ese mismo año el censor Juan Navarro de Espinosa ponía a que el protagonista de El purgatorio de San Patricio refiriera episodios de su vida, como vimos más arriba. La explicación no estaría tanto en el contraste de criterio entre un censor y otro, y que Calderón fuera "más benévolo", como comenta Regalado, sino en la diferencia entre censurar una obra de teatro o de cualquier otro género, porque no tenía la misma repercusión lo que se decía en el tablado a todo tipo de espectadores que lo que pocos podían leer en privado.

De Calderón es también una de las aprobaciones que van al frente de la Primera parte de Comedias de Don Juan de Matos Fragoso (Madrid, Julián de ParedesDomingo Palacio y Villegas, 1658), fechada el 13 de mayo de 1658. Nada contiene que contravenga la fe o las buenas costumbres que impida su publicación, a la que además obliga — viene a decir - su buena aceptación en las tablas, propuesta que incurre en una de las convenciones de este tipo de censuras, que es la de asociar el 
impreso con su vida escénica previa: "los aplausos que han merecido en los teatros traían anticipada la licencia que para su impresión pide".

Llevan también aprobaciones suyas otros dos volúmenes consecutivos de Comedias escogidas: la Parte veinte y tres (Madrid, Joseph Fernández de Buendía-Manuel Meléndez, 1665) y la Parte veinte y cuatro (Madrid, Mateo Fernández de Espinosa Arteaga-Juan de San Vicente, 1666), sin que en esta ocasión incluyan ninguna comedia del escritor. La fórmula utilizada es muy semejante, y de nuevo relaciona tablas y prensas, pero esta vez para apoyar que la falta de censura en los escenarios respalda el que se les conceda para la publicación: "habiéndolas antes oído representar sin censura - dice concretamente el segundo de los volúmenes-, y ahora leídolas con cuidado, no hallo inconveniente para que no puedan imprimirse".

El 20 de enero de 1681, pocos meses antes de su muerte, firmaba Calderón la más extensa de las aprobaciones vistas hasta ahora. Va al frente de la Citara de Apolo: varias poesías divinas y humanas, que escribió D. Agustín de Salazar y Torres y saca a la luz D. Juan de Vera Tasis y Villarroel. Primera parte (Madrid, Francisco Sanz, 1681). También es la más efusiva, por diferentes razones. En primer lugar, por el autor de los textos, Agustín de Salazar, del que precisamente el libro es su homenaje post mortem - Las obras póstumas de Don Agustín Salazar le da como título Calderón; de hecho, esta aprobación y las otras se presentan con posiciones y tipografía como si de unas piezas encomiásticas más se trataran. En segundo lugar, también tuvo que pesar la identidad - y los ruegos, tal vez- de su editor Juan de Vera Tassis, que al año siguiente lo sería también de sus comedias, publicadas póstumamente, a partir de la Verdadera quinta parte. Su amplitud y su edad podrían hacernos dudar de que hubiera sido escrita de su puño y letra en su integridad; sin embargo, inducen a creer que así fue la presencia, aunque amplificada y con algo más de pasión, de las mismas fórmulas que ha venido utilizando en su labor de censor: el respaldo para la aprobación de los aplausos logrados, que no obsta para que lo haya vuelto a leer, lo que ha hecho que su valoración sea aún más positiva; nada hay que "repugne a la pureza de la fe y buenas costumbres" y sí mucho que agradecer al editor que saca a la luz "este pulido tesoro de la lengua castellana".

Más allá de la calidad de la prosa utilizada en estos paratextos, tan valorada por E. M. Wilson [1963: 614-616] $]^{27}$, cabe concluir que Calderón como censor acostumbraba a ser más comedido que quienes censuraron sus obras. Y, desde luego, no... hizo gala en absoluto del ceño que frunce en el famoso retrato de Juan de Alfaro conservado en la Biblioteca Nacional, una de sus imágenes más difundidas, y quizá corresponsable de la severidad que durante tanto tiempo ha suscitado su figura.

\section{Bibliografía}

Aparicio Maydeu, Javier (1999): Calderón y la máquina barroca: escenografía, religión y cultura en El José de las mujeres, Amsterdam, Rodopi.

Bances Candamo, Francisco (1970): Theatro de los theatros de los passados y presentes siglos, ed. Duncan W. Moir, London, Tamesis.

27 E. M. Wilson finaliza su trabajo sobre las aprobaciones, con esta afirmación entusiasta: "Calderón —if he had chosen to write essays or novels - might have been one of the great masters of seventeenth-century prose" [1963: 616]. 
Barrionuevo de Peralta, Jerónimo (1892-1893): Avisos, Madrid, Impr. y Fundición de M. Tello, 4 vols.

Bergman, Ted L. (2002): "Los límites de la comicidad y la autocensura en las comedias de Calderón", en Ignacio Arellano, ed., Calderón 2000. Homenaje a Kurt Reichenberger en su 80 cumpleaños. Actas del Congreso Internacional, IV centenario del nacimiento de Calderón, Universidad de Navarra, septiembre 2000, Kassel, Edition Reichenberger: 961-970.

Bouza, Fernando (2012): “Dásele licencia y privilegio”. Don Quijote y la aprobación de libros en el Siglo de Oro, Madrid, Akal.

Calderón de la Barca, Pedro (1994): La vida es sueño, ed. José María Ruano de la Haza, Madrid, Castalia.

- (2005): Las órdenes militares, ed. José María Ruano de la Haza. Pamplona- Kassel, Universidad de Navarra-Edition Reichenberger.

- (2011): La selva confusa. Edición crítica y adaptación de Erik Coenen, Kassel, Reichenberger.

Černy, Vaclav (1962): “Une question à reprende: Wallenstein, héros d'un drame de Calderón”, Revue de Littérature Comparée, 36: 177-190.

Cotarelo y Mori, Emilio (2001): Ensayo sobre la vida y obras de D. Pedro Calderón de la Barca, Madrid, Tip. de la Rev. de Arch., Bibl. y Museos, 1924, ed. facsímil de I. Arellano y J. M. Escudero, Pamplona-Madrid-Frankfurt am Main, Universidad de Navarra-Iberoamericana-Vervuert.

Cruickshank, Don W. (1973): “The two editions de Calderón's Quinta parte”, en The Criticism of Calderón's Comedias, vol. I de Pedro Calderón de la Barca: Comedias. A facsimile edition, eds. D. W. Cruickshank y J. E. Varey, London, Gregg International Publishers - Tamesis Books: 201-210.

- (2002): "La crítica discreta del poder en la obra calderoniana de la primera época", en Ayer y hoy de Calderón. Actas seleccionadas del Congreso Internacional celebrado en Ottawa del 4 al 8 de octubre del 2000, Madrid, Editorial Castalia: 95-106.

Hernando Morata, Isabel (2017-2018): "El Memorial de Paravicino contra Calderón y el Parecer de Trejo", Boletín de la Biblioteca de Menéndez Pelayo, 93-94: 93-130.

Herzig, Carine (2008): "La polémica en torno a la Aprobación del Padre Fray Manuel de Guerra y Ribera (1682-1684) y la moralización de la Comedia”, Criticón, 103-104: 81-92.

Regalado García, Antonio (1995): Calderón: los orígenes de la modernidad en la España del Siglo de Oro, Barcelona, Destino.

Reichenberger, Kurt y Roswita (1979): Bibliographisches Handbuch der Calderón Forschung / Manual bibliográfico calderoniano, Kassel, Verlag Thiele und Schwarz, vol. 1.

Ruano de la Haza, José M. (1992): La primera versión de "La vida es sueño”, de Calderón, Liverpool, Liverpool University Press.

Rubiera, Javier (2006): "Un demonio de ida y vuelta. Sobre la edición de las acotaciones en El José de las mujeres", en Anthony Close, ed., Edad de Oro cantabrigense. Actas del VII Congreso de la Asociación Internacional del Siglo de Oro (Cambridge, julio de 2005), Madrid, Iberoamericana-Vervuert: 545-550.

- (2011): "Teología contra dramática: a vueltas con el demonio en El José de las mujeres calderoniano", en Antonio Azaustre Galiana y Santiago Fernández Mosquera, eds., Compostella Aurea. Actas del VIII Congreso de la AISO. Santiago de Compostela, 7-11 de julio de 2008, Santiago de Compostela, Universidad de Santiago de Compostela: 1313-1320.

Sanz Ayán, Carmen (2006): Pedagogía de reyes: el teatro palaciego en el reinado de Carlos II, Madrid, Real Academia de la Historia. 
Sullivan, Henry W. (2000): “The Wallenstein Play of Calderón and Coello, Las proezas de Frislán, y muerte del rey de Suecia [?] (1634): Conjectural Reconstruction”, Bulletin of the Comediantes, 52/2: 93-111.

Torres, José Carlos de y Enrique Rull Fernández (1981): Calderón y Hördlingen. El auto El Primer blasón del Austria de don Pedro Calderón de la Barca, Madrid, Consejo Superior de Investigaciones Científicas.

Urzáiz Tortajada, Héctor, dir., Censuras y licencias en manuscritos e impresos teatrales (CLEMIT), base de datos, http://www.clemit.es/.

Vega García-Luengos, Germán (2001): “Calderón y la política internacional: las comedias sobre el héroe y traidor Wallenstein”, en José Alcalá Zamora y Ernest Belenguer, eds., Calderón de la Barca y la España del Barroco, Madrid, Centro de Estudios Políticos y Constitucionales-Sociedad Estatal España Nuevo Milenio: 793-827.

- (2007): "Las credenciales calderonianas de otra comedia rechazada por Calderón: El perdón castiga más", en Odette Gorsse y Frédéric Serralta, eds., El Siglo de Oro en escena. Homenaje a Marc Vitse, Toulouse, Presses Universitaires du Mirail-Consejería de Educación de la Embajada de España en Francia (Anejos de Criticón): 1053-1069.

- (2008): "Consideraciones sobre la configuración del legado de comedias de Calderón", Criticón (Ejemplar dedicado a "La literatura española en tiempos de los novatores. 16751726"), 103-104: 249-271.

- (2012): "Presencias de Europa en el teatro español del siglo XVII", en Europa (historia y mito) en la comedia española. XXXIII Jornadas de Teatro Clásico, Almagro, 6, 7 y 8 de julio de 2010, Ciudad Real, Universidad de Castilla-La Mancha, Ediciones de la Universidad de Castilla-La Mancha: 33-52.

- (2013): “El Calderón que olvidó o repudió Calderón”, en Alain Bègue y Emma Herrán Alonso, eds., Pictavia Aurea. Actas del IX Congreso de la Asociación Internacional "Siglo de Oro" (Poitiers, 11-15 de julio de 2011), Toulouse, Presses Universitaires du Mirail (Anejos de Criticón 19): 111-142.

Wilson, Edward M. (1961a): "Calderón and the Stage-censor in the Seventeenth Century. A Provisional Study", Symposium, 15/3: 165-184.

- (1961b): "Fray Hortensio Paravicino's protest against El príncipe constante", Ibérida: Revista de Filología, 6: 245-266.

- (1963): "Seven 'Aprovaciones' by Pedro Calderón de la Barca", en Homenaje ofrecido a Dámaso Alonso por sus amigos y discípulos con ocasión de su $60^{\circ}$ aniversario, Madrid, Gredos: III, 605-618.

- (1967): "Nuevos documentos sobre las controversias teatrales: 1650-1681", en Actas del Segundo Congreso Internacional de Hispanistas, Nimega, Instituto Español de la Universidad de Nimega: 155-170. 
